\title{
Variation of Meiotic Recombination Rates and MLH1 Foci Distribution in Spermatocytes of Cattle, Sheep and Goats
}

\author{
Jan Fröhlich Miluse Vozdova Svatava Kubickova Halina Cernohorska \\ Hana Sebestova Jiri Rubes \\ Central European Institute of Technology - Veterinary Research Institute, Brno, Czech Republic
}

\section{Key Words}

Immunofluorescence · Meiosis · Recombination .

Spermatocyte $\cdot$ Synaptonemal complex

\begin{abstract}
Despite similar genome sizes, a great variability in recombination rates is observed in mammals. We used antibodies against SYCP3, MLH1 and centromeres to compare crossover frequency, position along chromosome arms and the effect of crossover interference in spermatocytes of 4 species from the family Bovidae (Bos taurus, $2 \mathrm{n}=60$, tribe Bovini; Ovis aries, $2 \mathrm{n}=54$, Capra hircus, $2 \mathrm{n}=60$ and Ammotragus lervia, $2 n=58$, tribe Caprini). Despite significant individual variability, our results also show significant differences in both recombination rates and the total length of autosomal synaptonemal complexes (SC) between cattle (47.53 MLH1 foci/cell, $244.59 \mu \mathrm{m}$ ) and members of the tribe Caprini ( 61.83 MLH1 foci, $296.19 \mu \mathrm{m}$ ) which can be explained by the length of time that has passed since their evolutionary divergence. Sheep displayed the highest number of MLH1 foci per cell and recombination density, although they have a lower diploid chromosome number caused by centric fusions corresponding to cattle chromosomes 1;3, 2;8 and 5;11. However, the proportion of MLH1 foci observed on the fused chromo-
\end{abstract}

somes in sheep (26.14\%) was significantly lower than on the orthologous acrocentrics in cattle (27.6\%) and goats (28.2\%), and their distribution along the SC arms differed significantly. The reduced recombination rate in metacentrics is probably caused by interference acting across the centromere.

(c) 2015 S. Karger AG, Basel

In all organisms which reproduce sexually, homologous chromosome synapsis and recombination play a crucial role in the correct segregation of chromosomes into gametes, as well as in creating genetic diversity for natural selection. The physical link between homologous chromosomes, mediated by crossing over, serves as a bond which helps paired chromosomes to align properly in the meiotic metaphase plate and segregate correctly to the opposite sides of the dividing cell, thus providing balanced gametes [Hassold et al., 2000; Cohen et al., 2006; Coop and Przeworski, 2007]. In mammalian males, disruption of chromosome pairing and inability to execute crossing over is usually connected with a complete failure to produce viable gametes [Sciurano et al., 2012].

Regardless of the importance of recombination, our knowledge of the mechanism which determines the number and position of crossover (CO) foci along chromo-

\section{KARGER 125\%}

(c) 2015 S. Karger AG, Base

$1424-8581 / 15 / 1463-0211 \$ 39.50 / 0$

E-Mail karger@karger.com

www.karger.com/cgr 
some arms is still not completely clear. On the other hand, it is well known that the gender of animals, chromosome size, DNA sequence, chromatin structure, and CO interference are a few factors which influence the rate and pattern of recombination [Robinson, 1996; Kong et al., 2002; Lynn et al., 2002; Borodin et al., 2007; Mary et al., 2014]. Also, despite a quite similar mammalian genomic size of $3 \times 10^{9}$ bases, a great interspecific variability in recombination rates is observed. This phenomenon is probably caused by the number of chromosomes, which is usually different amongst various mammalian species, and by the fact that for correct segregation of the chromosomes into gametes, there is a need for at least 1 obligatory recombination nodule per chromosome bivalent, but additional COs often occur [Hultén, 1974; Pardo-Manuel de Villena and Sapienza, 2001; Fledel-Alon et al., 2009; Groenen et al., 2009]. Moreover, in mammals, there is a stronger correlation between the number of chiasmata and chromosome arms than between chiasmata and chromosome number [Pardo-Manuel de Villena and Sapienza, 2001; Segura et al., 2013].

For the estimation of frequency and physical localization of recombination sites along chromosome arms, immunofluorescent labeling of the synaptonemal complex protein (SYCP3) and MLH1 protein (eukaryotic homolog of bacterial mismatch repair protein mutL) is one of the reliable and frequently used methods [Barlow and Hultén, 1998; Anderson et al., 1999; Sun et al., 2004]. As it has been shown elsewhere [Baker et al., 1996; Froenicke et al., 2002], MLH1 is part of a multiprotein complex localized in late recombination nodules. Thus, the number of MLH1 foci directly corresponds to the number of $\mathrm{CO}$ events.

The vast majority of papers which focus on mammalian meiosis and the process of recombination deal with humans or mice [Lynn et al., 2002; Jensen-Seaman et al., 2004], but in recent years many other mammalian species have been studied [Borodin et al., 2007, 2008; Basheva et al., 2008; Dumont and Payseur, 2011; Garcia-Cruz et al., 2011; Yang et al., 2011; Segura et al., 2013; Vozdova et al., 2013; Al-Jaru et al., 2014; Mary et al., 2014].

In our study, we focused on the evaluation of the number of COs, their position along chromosome arms, as well as the effect of CO interference in 4 species from the family Bovidae, namely 3 economically important domestic species (Bos taurus, BTA, $2 \mathrm{n}=60$, tribe Bovini; Ovis aries, $\mathrm{OAR}, 2 \mathrm{n}=54$ and Capra hircus, $\mathrm{CHI}, 2 \mathrm{n}=60$, both tribe Caprini) and 1 wildlife representative from the tribe Caprini (Ammotragus lervia, ALE, $2 \mathrm{n}=58$ ). Generally, the species of the Bovidae family are characterized by significant differences in their diploid chromosome num- ber, despite the fact that their karyotypes are closely related. The ancestral karyotype of the family Bovidae is still present (with minor variations) in cattle and goats $(2 \mathrm{n}=$ 60 ) with 29 pairs of acrocentric autosomes and the $X$ and Y chromosomes [Gallagher et al., 1994]. During evolution and speciation, chromosomes in the majority of species of this family underwent chromosomal rearrangements, mostly Robertsonian fusions (centric fusions), which result in the formation of metacentric chromosomes [Hassanin and Douzery, 1999]. This happened several times in the evolution of sheep because 3 metacentric chromosomes are present in their karyotype. The arms of sheep chromosome 1 (OAR1) correspond to cattle/goat chromosomes 1 and 3 (BTA1;3); sheep chromosome 2 (OAR2) corresponds to BTA2;8, and sheep chromosome 3 (OAR3) to BTA5;11. This difference in chromosome number between cattle/goats and sheep gives us an opportunity to compare the distribution of homologous recombination in these species and to evaluate the influence of centric fusions on meiotic recombination.

\section{Material and Methods}

\section{Animals}

Testicular samples were obtained post mortem from 4 bulls (BTAI-BTAIV, average age of 24 months, Czech spotted cattle breed), 11 sheep (OARI-OARXI, average age of 7 months, mixed breed), 8 goats (CHII-CHIVIII, average age of 9 months, pygmy goat breed) and 1 Barbary sheep (ALE, age of 9 years). The bulls and sheep were slaughtered for meat production at a local abattoir, and the goats and the Barbary sheep were killed by a veterinarian when culling the breeding herd at a local zoo. The age of individual animals and their breed are shown in online supplementary table 1 (see www.karger.com/doi/10.1159/000439452 for all online suppl. material). All institutional and national guidelines for the care and use of laboratory animals were followed.

\section{Sample Processing}

As a starting material for our immunofluorescent analyses, we used whole testicles which had been transported to our laboratory on ice. They were then processed by cutting them into small pieces and stored frozen in tubes at $-80^{\circ} \mathrm{C}$. Before sample freezing, a small portion of the tissue was directly subjected to fixation and immunolabeling. Briefly, a small piece of testicular tissue was minced in a tube with PBS. After sedimentation of larger pieces, pure cell suspension without tissue debris was transferred to a clean tube and centrifuged for $5 \mathrm{~min}$ at $600 \mathrm{~g}$. In the next step, the supernatant was discarded and the remaining pellet was resuspended in PBS. A 10- $\mu$ d drop of the cell suspension was mixed on a microscopic slide (Super-Frost; Menzel, Braunschweig, Germany) with $10 \mu \mathrm{l}$ of spreading solution containing $0.05 \%$ Triton (Fluka Chemie, Buchs, Switzerland) in distilled water, smeared and left to dry slowly in a humid chamber. The smears were then covered with $80 \mu \mathrm{l}$ of $0.015 \%$ Igepal (Sigma-Aldrich) in $\mathrm{H}_{2} \mathrm{O}$ for $5 \mathrm{~min}$ and 
fixed with $120 \mu \mathrm{l}$ of $1 \%$ paraformaldehyde/0.016\% Triton/PBS for $10 \mathrm{~min}$ in a humid chamber. Finally, the slides were rinsed with distilled water and placed in a jar with $80 \mathrm{~mm}$ Tris- $\mathrm{HCl} / 150 \mathrm{mM}$ $\mathrm{NaCl} / 0.1 \%$ Tween (TNT).

\section{Immunostaining}

Briefly, the rabbit polyclonal anti-MLH1 antibody (Santa Cruz Biotechnology Inc., Santa Cruz, Calif., USA) was diluted 1:50 in $0.55 \% \mathrm{BSA} / 0.1 \%$ Tween/PBS and applied to each of the paraformaldehyde-fixed slides. Then, the slides were covered with plastic coverslips of $24 \times 32 \mathrm{~mm}$ and incubated at $37^{\circ} \mathrm{C}$ overnight in a humid chamber. Afterwards, the slides were washed twice in TNT for $3 \mathrm{~min}$, and secondary antibody (donkey anti-rabbit-FITC, Santa Cruz Biotechnology) diluted 1:100 was applied to the slides, followed by incubation in a humid chamber at $37^{\circ} \mathrm{C}$ for $1 \mathrm{~h}$. After washing $(2 \times 3 \mathrm{~min}$ in TNT), the rabbit polyclonal anti-SYCP3 (Abcam, Cambridge, UK) and the human anti-centromere antibodies (Antibodies Inc., Davis, Calif., USA) diluted 1:100 were deposited on the slides and were left in high humidity at $37^{\circ} \mathrm{C}$ overnight. The slides were washed twice in TNT for $3 \mathrm{~min}$, secondary antibodies (donkey anti-rabbit-Texas Red, Santa Cruz Biotechnology; and donkey anti-human-AMCA, Jackson Immunoresearch, USA) diluted 1:100 were applied, and the slides were incubated in a humid chamber at $37^{\circ} \mathrm{C}$. After $1 \mathrm{~h}$ incubation, the slides were finally washed twice in TNT for 3 min and carefully mounted in Vectashield mounting medium (Vector Laboratories, Burlingame, Calif., USA).

\section{Analysis}

For the analysis, an Olympus BX60 fluorescence microscope equipped with appropriate fluorescent filters was used. Images of well-spread pachytene spermatocytes with MLH1 signals were captured by a CoolCube CCD camera (MetaSystems, Altlussheim, Germany). The number of MLH1 foci (recombination sites) per cell, distance of MLH1 foci from the centromere $(\mu \mathrm{m})$ and all SC lengths $(\mu \mathrm{m})$ were scored using Isis3 software (MetaSystems).

\section{Fluorescence in situ Hybridization}

After immunofluorescence analysis, the slides for FISH analysis were washed in TNT for 5 min and fixed in PBS with 1\% paraformaldehyde for $5 \mathrm{~min}$. Slides for metaphase analysis (i.e. mitotic chromosomes) were prepared as described elsewhere [Kubickova et al., 2002]. Both types of slides were then dehydrated in a graded ethanol series (70, 85 and 96\%) and subjected to FISH. The painting probes were prepared by DOP-PCR amplification with subsequent labeling of DNA from bovine chromosomes obtained by laser microdissection as described earlier [Kubickova et al., 2002]. Probes for the whole chromosomes BTA3, 5, 8 and for the distal parts of BTA1, 2 and 11 were labeled with Spectrum Green or Spectrum Orange (Vysis, Richmond, UK). The slides were denatured in $70 \%$ formamide $/ 2 \times \mathrm{SSC}(\mathrm{pH} 7.2)$ at $72^{\circ} \mathrm{C}$ for $2 \mathrm{~min}$, dehydrated in a cold ethanol series and air-dried. Then, $10 \mu \mathrm{l}$ of the hybridization mixture containing $50 \%$ formamide, $2 \times$ SSC, $10 \%$ dextran sulfate, $0.7 \mu \mathrm{g} / \mu \mathrm{l}$ salmon sperm, $0.13 \mu \mathrm{g} / \mu \mathrm{l}$ Bovine Hybloc DNA (Applied Genetics Laboratories, Melbourne, Fla., USA) and $10 \mathrm{ng} / \mu \mathrm{l}$ of the labeled DNA probe were denatured at $75^{\circ} \mathrm{C}$ for $10 \mathrm{~min}$ and preannealed at $37^{\circ} \mathrm{C}$ for $30 \mathrm{~min}$. After hybridization in a humid chamber at $37^{\circ} \mathrm{C}$ overnight, the slides were washed in $0.7 \times \mathrm{SSC}$ at $72^{\circ} \mathrm{C}$ for $2 \mathrm{~min}$ and mounted in Vectashield mounting medium (Vector Laboratories). Two rounds of FISH with a combination of

Meiotic Recombination in Cattle, Sheep and Goats
3 probes (whole chromosome or partial painting probes) were used for the identification of chromosomes BTA1, 2, 3, 5, 8, and 11 and their orthologs in cattle, sheep and goat mitoses and in the pachytene spermatocytes.

Images of spermatocytes previously analyzed for the number of MLH1 foci and SC length were recaptured, and the distribution of MLH1 foci along the synaptonemal complex (SC) arms corresponding to chromosomes BTA1, 2, 3, 5, 8, and 11 was studied. Measurements of the lengths of SCs, metaphase chromosomes and assessment of the relative positions of MLH1 foci on the chromosomes studied in detail were performed using Isis software.

\section{Statistical Analysis}

Statistical analysis was performed by the nonparametric MannWhitney exact test and Spearman's bivariate correlation using the SPSS software package, version 22 for Windows (SPSS Inc., Chicago, Ill., USA).

\section{Results}

A total of 3,010 pachytene spermatocytes (minimum of 100 pachytene cells from each of the 24 animals) were evaluated for CO frequency, with 175,680 MLH1 foci recorded in total. Examples of well-spread, representative pachytene spermatocytes of a bull and a ram are shown in figure 1.

In all animals, the observed number of MLH1 foci was much higher than the minimum of 29 CO loci expected, assuming that at least $1 \mathrm{CO}$ per chromosome bivalent is necessary for proper meiotic segregation of homologous chromosomes in bovids (ancestral karyotype with 29 pairs of acrocentric autosomes). SCs lacking an MLH1 focus were rare. The mean numbers of MLH1 foci per cell in the studied species are shown in figure 2 and table 1. Significant differences in the mean number of MLH1 foci per cell were found among the studied species. The observed meiotic recombination frequency in cattle was significantly lower $(\mathrm{p}<0.001)$ than in species from the tribe Caprini (fig. 2). A significant interindividual variability in recombination counts was noted among individual animals of the same species $(\mathrm{p}<0.001)$. Data are displayed in online supplementary table 1.

The total lengths of autosomal SCs were measured in at least 60 well-spread pachytene spermatocytes of cattle, sheep and goats and in 30 pachytene cells from Barbary sheep (table 1). Significant interspecific differences in the total length of SCs $(\mathrm{p}<0.001)$ were found (data shown in table 1). The total mean length of all autosomal SCs in bulls $(244.59 \pm 15.8 \mu \mathrm{m})$ was significantly lower $(\mathrm{p}<$ $0.001)$ than in the tribe Caprini $(262.96 \pm 21.5 \mu \mathrm{m}$ in sheep, $328.38 \pm 23.5$ in goats, $297.23 \pm 24.9$ in Barbary sheep). 

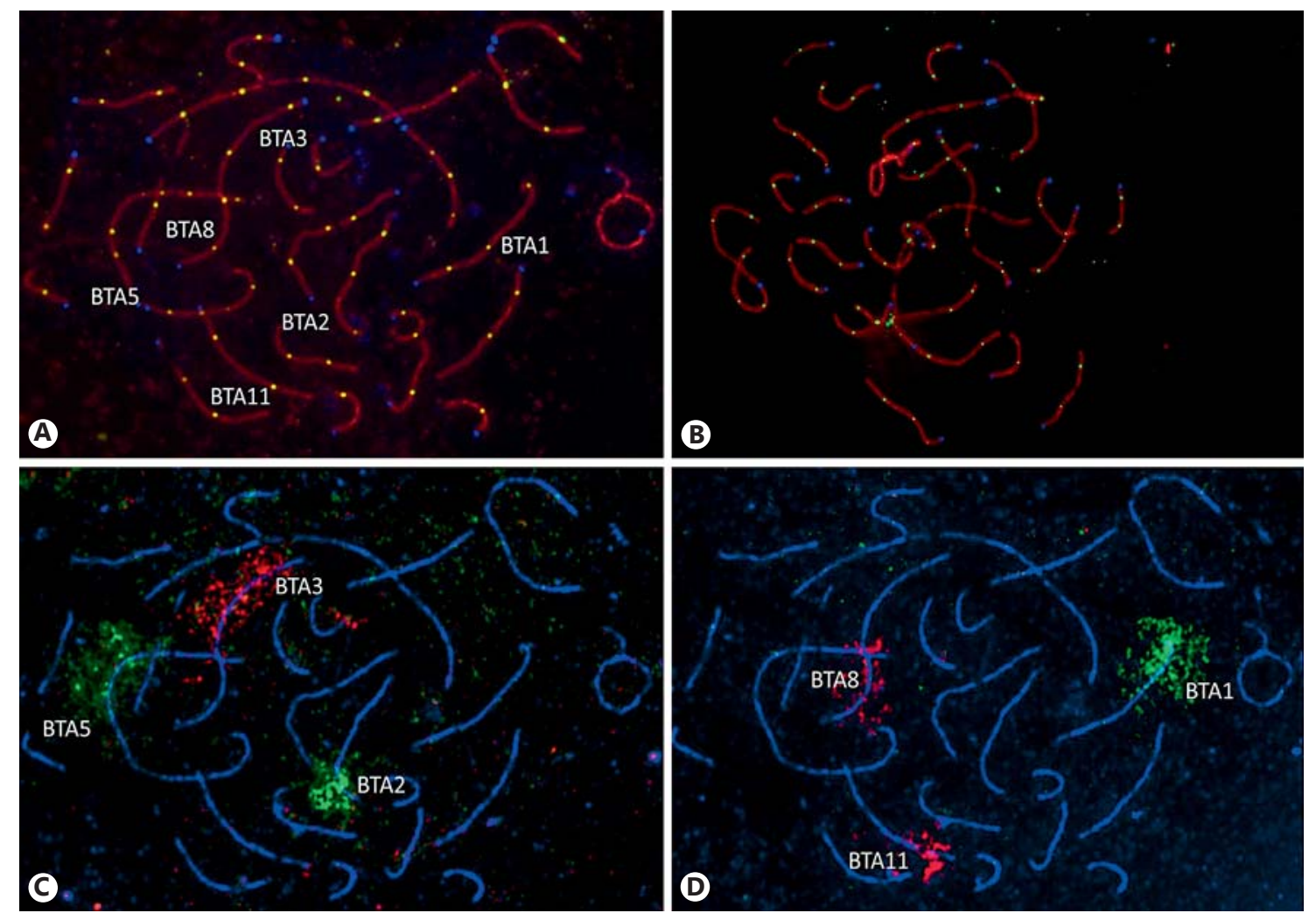

Fig. 1. A, B Pachytene spermatocytes of a bull (A) and a ram (B) immunolabeled with antibodies to SCP3 (red), MLH1 (yellow) and centromeres (blue). C, D Immunolabeled pachytene spermatocyte (shown in A) after FISH with painting probes specific for chromosomes BTA2, 3 and 5 (C) and for BTA1, 8 and 11 (D).

Table 1. Frequency of MLH1 foci, total length of SCs and crossover density in the studied species

\begin{tabular}{|c|c|c|c|c|c|c|c|}
\hline Species & $\begin{array}{l}\text { Animals, } \\
\mathrm{n}\end{array}$ & $\begin{array}{l}\text { Cells, } \\
\mathrm{n}\end{array}$ & $\begin{array}{l}\text { Autosomal } \\
\text { MLH1 foci/cell }\end{array}$ & $\begin{array}{l}\text { Range of } \\
\text { MLH1 foci }\end{array}$ & $\begin{array}{l}\text { MLH1 foci } \\
\text { on XY'b } \%\end{array}$ & $\begin{array}{l}\text { Total SC length }{ }^{\mathrm{a}} \text {, } \\
\mu \mathrm{m}\end{array}$ & $\begin{array}{l}\text { MLH1 foci/ } \mu \mathrm{m} \\
\text { of SC }\end{array}$ \\
\hline Cattle & 4 & 720 & $47.53 \pm 4.26$ & $36-60$ & 17.47 & $244.59 \pm 15.79$ & $0.196 \pm 0.017^{\mathrm{d}}$ \\
\hline Sheep & 11 & 1297 & $62.90 \pm 6.04$ & $41-88$ & 38.72 & $262.96 \pm 21.51$ & $0.244 \pm 0.021$ \\
\hline Goats & 8 & 886 & $60.59 \pm 5.21^{\mathrm{c}}$ & $44-81$ & 27.71 & $328.38 \pm 23.49$ & $0.184 \pm 0.016$ \\
\hline Barbary sheep & 1 & 107 & $57.95 \pm 5.03^{c}$ & $45-73$ & 20.56 & $297.23 \pm 24.88$ & $0.199 \pm 0.022^{\mathrm{d}}$ \\
\hline
\end{tabular}

${ }^{a}$ Values are means \pm SD. ${ }^{b}$ Percentage of cells. ${ }^{c}$ No statistically significant difference was found between MLH1 counts in Barbary sheep and goats. ${ }^{d}$ No statistical significance was found between Barbary sheep and cattle in MLH1 density. Differences in all other species combinations were statistically highly significant $(\mathrm{p}<0.001)$.

No statistically significant correlation was found between the number of recombination foci and the total length of SCs in any studied species. On the other hand, a significant correlation was found between the length of individual SCs and the corresponding MLH1 foci counts in bulls $(\mathrm{r}=0.642, \mathrm{p}<0.001)$, rams $(\mathrm{r}=0.638, \mathrm{p}<0.001)$ and goats $(\mathrm{r}=0.374, \mathrm{p}<0.001)$.
The next examined parameter was recombination density. It was calculated as the number of MLH1 foci divided by the total autosomal SC length per cell. As expected, total CO density was significantly higher in sheep $(0.244 \pm 0.021 \mathrm{MLH} 1 \mathrm{foci} / \mu \mathrm{m})$ than in the other studied species $(\mathrm{p}<0.001)$ (table 1$)$. The lowest recombination density was observed in goats $(0.184 \pm 0.016 \mathrm{MLH} 1$ foci/ 


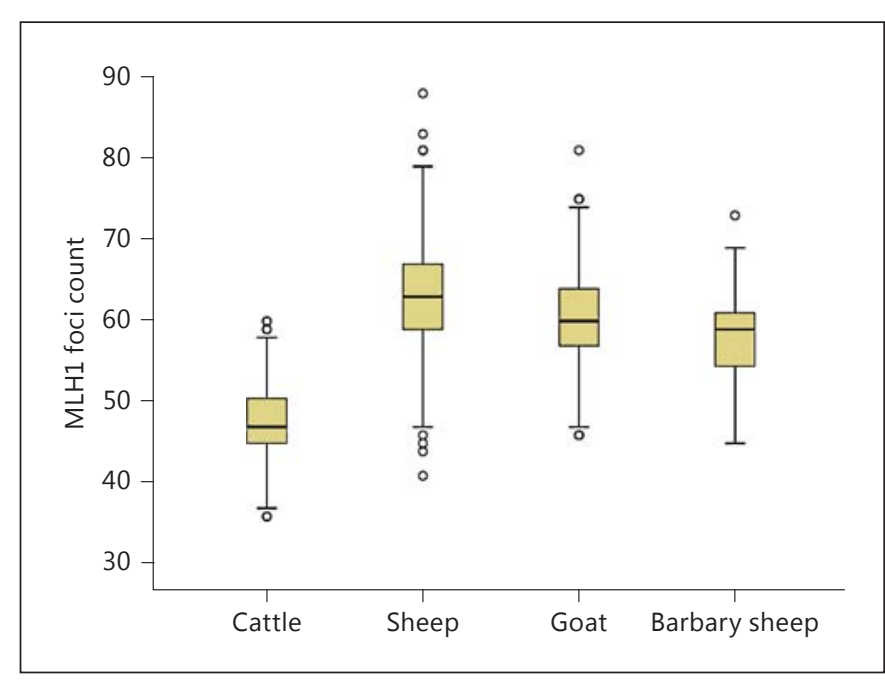

Fig. 2. Frequency of meiotic recombination in the studied species. Note the similar recombination rates amongst species from the tribe Caprini. The height of each box represents the $25-75 \%$ data range, the horizontal line within each box represents the median value, and the upper and lower extensions represent the largest and smallest values. MLH1 counts which fell more than 1.5 box-lengths from the 25th and 75th percentile of the distribution were considered as outlier values (open circles). The mean numbers of COs per cell differed significantly $(\mathrm{p}<0.001)$ among the studied species.

$\mu \mathrm{m})$, whereas recombination density in cattle and Barbary sheep was similar to each other, despite different total SC lengths and MLH1 foci counts $(0.196 \pm 0.017$ MLH1 foci/ $\mu \mathrm{m}$ and $0.199 \pm 0.022 \mathrm{MLH} 1$ foci $/ \mu \mathrm{m}$, respectively).

The number of MLH1 foci and their positions on the individual SCs corresponding to bovine chromosomes BTA1, 2, 3, 5, 8, and 11 and their orthologs were analyzed in cattle, sheep and goats (table 2). The relative lengths of some of the studied SCs in cattle and sheep did not correspond to their relative lengths in mitosis.

The density of recombination on the metacentric chromosomes of sheep (BTA1;3, BTA2;8, BTA5;11) was significantly higher than on their acrocentric orthologs in cattle and goats as expected based on the total recombination density. Nevertheless, the recombination density on these chromosomes in bulls and sheep, but not in goats (data shown in table 2) was significantly lower than the total average recombination density counted for these species $(\mathrm{p}<0.001)$ (table 1$)$. The relative numbers of $\mathrm{CO}$ events located on the 3 metacentric chromosomes in sheep (counted as a percentage of all MLH1 foci present in the cell) were significantly lower than on their ortho-
Table 2. SC lengths and recombination densities on bovine chromosomes 1, 2, 3, 5, 8, and 11 and their orthologs in sheep and goats

\begin{tabular}{lllll}
\hline $\begin{array}{l}\text { Chromo- } \\
\text { some }\end{array}$ & & $\begin{array}{l}\text { Cattle } \\
(\mathrm{n}=60)\end{array}$ & $\begin{array}{l}\text { Sheep } \\
(\mathrm{n}=87)\end{array}$ & $\begin{array}{l}\text { Goats } \\
(\mathrm{n}=61)\end{array}$ \\
\hline 1 & SC length, $\mu \mathrm{m}$ & $13.5 \pm 1.5$ & $14.5 \pm 1.8$ & $\begin{array}{l}17.7 \pm 2.3 \\
\end{array}$ \\
& MLH1 foci & $2.35 \pm 0.48$ & $3.09 \pm 0.68$ & $3.23 \pm 0.59$ \\
& MLH1 density & $0.18 \pm 0.05$ & $0.22 \pm 0.05$ & $0.18 \pm 0.03$ \\
\hline 2 & SC length, $\mu \mathrm{m}$ & $12.2 \pm 1.2$ & $13.6 \pm 2.2$ & $16.6 \pm 1.9$ \\
& MLH1 foci & $2.25 \pm 0.60$ & $2.85 \pm 0.62$ & $2.93 \pm 0.60$ \\
& MLH1 density & $0.19 \pm 0.05$ & $0.21 \pm 0.06$ & $0.18 \pm 0.04$ \\
\hline 3 & SC length, $\mu \mathrm{m}$ & $12.3 \pm 1.4$ & $13.7 \pm 2.3$ & $15.9 \pm 1.7$ \\
& MLH1 foci & $2.22 \pm 0.49$ & $2.89 \pm 0.65$ & $2.93 \pm 0.60$ \\
& MLH1 density & $0.18 \pm 0.04$ & $0.22 \pm 0.06$ & $0.19 \pm 0.04$ \\
\hline 5 & SC length, $\mu \mathrm{m}$ & $11.5 \pm 1.6$ & $12.9 \pm 1.8$ & $15.3 \pm 2.1$ \\
& MLH1 foci & $2.12 \pm 0.45$ & $2.76 \pm 0.65$ & $2.74 \pm 0.57$ \\
& MLH1 density & $0.19 \pm 0.04$ & $0.22 \pm 0.06$ & $0.18 \pm 0.04$ \\
\hline 8 & SC length, $\mu \mathrm{m}$ & $10.2 \pm 1.2$ & $11.5 \pm 1.9$ & $14.1 \pm 16$ \\
& MLH1 foci & $1.97 \pm 0.45$ & $2.45 \pm 0.66$ & $2.51 \pm 0.57$ \\
& MLH1 density & $0.19 \pm 0.05$ & $0.22 \pm 0.07$ & $0.18 \pm 0.04$ \\
\hline 11 & SC length, $\mu \mathrm{m}$ & $11.3 \pm 1.5$ & $11.7 \pm 1.9$ & $13.6 \pm 1.7$ \\
& MLH1 foci & $1.85 \pm 0.48$ & $2.52 \pm 0.66$ & $2.59 \pm 0.66$ \\
& MLH1 density & $0.17 \pm 0.04$ & $0.22 \pm 0.06$ & $0.19 \pm 0.04$ \\
\hline
\end{tabular}

Data are expressed as means $\pm \mathrm{SD}$.

logs in cattle and goats ( 26.1 vs. 27.6 and $28.23 \%$, respectively, $\mathrm{p}<0.001$ ).

For the exclusion of possible chromosome shortening by formation of Robertsonian fusions during karyotype evolution in the sheep, as a potential factor for reduced recombination counts, FISH analysis was performed on mitotic chromosomes, and relative lengths (the length of individual mitotic chromosomes divided by the total length of all mitotic chromosomes in the cell) of sheep metacentric chromosome arms were compared with relative lengths of their acrocentric orthologs in cattle and goats (table 3). Only minor differences were found between the studied species. Our results were supported by the data obtained from bovine, ovine and goat genomic libraries available at the NCBI database [Bovine Genome Sequencing and Analysis Consortium et al., 2009; International Sheep Genomics Consortium et al., 2010; Dong et al., 2013] (table 3).

In cattle and sheep, the positions of the recombination events along all SC arms were evaluated as their relative distance from the centromere (measured as \% of the SC arm length). Distribution of MLH1 foci along SC arms was observed to be non-coincidental, with non-random 
Table 3. Relative lengths of sheep metacentric chromosomes and their acrocentric orthologs in cattle and goats compared with data obtained from cattle, sheep and goat genomic libraries

\begin{tabular}{|c|c|c|c|c|c|c|c|}
\hline \multirow[t]{2}{*}{ Species } & \multirow{2}{*}{$\begin{array}{l}\text { Total genomic } \\
\text { length, } \mathrm{Mb}\end{array}$} & \multicolumn{2}{|l|}{ Chr1 + Chr3 } & \multicolumn{2}{|l|}{ Chr2 + Chr8 } & \multicolumn{2}{|l|}{ Chr5 + Chr11 } \\
\hline & & genomic library & $\begin{array}{l}\text { experimental } \\
\text { data }^{\mathrm{a}}\end{array}$ & genomic library & $\begin{array}{l}\text { experimental } \\
\text { data }^{\mathrm{a}}\end{array}$ & genomic library & $\begin{array}{l}\text { experimental } \\
\text { data }^{\mathrm{a}}\end{array}$ \\
\hline Cattle & $2,670^{\mathrm{b}}$ & $279 \mathrm{Mb}(10.4 \%)$ & $10.47 \pm 0.65$ & $250 \mathrm{Mb}(9.4 \%)$ & $9.32 \pm 0.69$ & $228 \mathrm{Mb}(8.5 \%)$ & $8.48 \pm 0.52$ \\
\hline Sheep & $2,619^{c}$ & $280 \mathrm{Mb}(10.7 \%)$ & $10.47 \pm 0.65$ & $250 \mathrm{Mb}(9.5 \%)$ & $9.37 \pm 0.48$ & $224 \mathrm{Mb}(8.6 \%)$ & $8.41 \pm 0.48$ \\
\hline Goats & $2,660^{\mathrm{d}}$ & $272 \mathrm{Mb}(10.2 \%)$ & $10.90 \pm 0.32$ & $246 \mathrm{Mb}(9.2 \%)$ & $9.47 \pm 0.44$ & $216 \mathrm{Mb}(8.1 \%)$ & $8.41 \pm 0.36$ \\
\hline
\end{tabular}

${ }^{a}$ Values are calculated as percentage of the total chromosome length in the cell and given as mean $\pm \mathrm{SD}$.

${ }^{\mathrm{b}}$ Bovine Genome Sequencing and Analysis Consortium et al., 2009. ${ }^{\mathrm{c}}$ International Sheep Genomics Consortium et al., 2010. ${ }^{\mathrm{d}}$ Dong et al., 2013.

Table 4. Distribution of MLH1 foci along all SC arms in cattle and sheep

\begin{tabular}{|c|c|c|c|c|c|}
\hline \multirow{2}{*}{$\begin{array}{l}\text { MLH1 } \\
\text { foci, } n\end{array}$} & & \multicolumn{2}{|l|}{ Cattle } & \multicolumn{2}{|l|}{ Sheep } \\
\hline & & $\begin{array}{l}\text { MLH1 } \\
\text { position }\end{array}$ & SCs, $\mathrm{n}$ & $\begin{array}{l}\text { MLH1 } \\
\text { position }\end{array}$ & SC arms, n \\
\hline 1 & 1 st & $0.55 \pm 0.22$ & $711(40.86 \%)$ & $0.53 \pm 0.19$ & $236(13.56 \%)$ \\
\hline 2 & $\begin{array}{l}\text { 1st } \\
\text { 2nd }\end{array}$ & $\begin{array}{l}0.27 \pm 0.13 \\
0.81 \pm 0.13\end{array}$ & $906(52.07 \%)$ & $\begin{array}{l}0.25 \pm 0.14 \\
0.80 \pm 0.13\end{array}$ & $966(55.52 \%)$ \\
\hline 3 & $\begin{array}{l}1 \mathrm{st} \\
2 \mathrm{nd} \\
3 \mathrm{rd}\end{array}$ & $\begin{array}{l}0.17 \pm 0.10 \\
0.50 \pm 0.14 \\
0.87 \pm 0.10\end{array}$ & $113(6.49 \%)$ & $\begin{array}{l}0.16 \pm 0.09 \\
0.51 \pm 0.13 \\
0.87 \pm 0.10\end{array}$ & $484(27.82 \%)$ \\
\hline 4 & $\begin{array}{l}1 \text { st } \\
2 \text { nd } \\
3 \text { rd } \\
4 \text { th }\end{array}$ & $\begin{array}{l}0.11 \pm 0.04 \\
0.28 \pm 0.05 \\
0.47 \pm 0.09 \\
0.76 \pm 0.19\end{array}$ & $2(0.11 \%)$ & $\begin{array}{l}0.11 \pm 0.07 \\
0.36 \pm 0.10 \\
0.63 \pm 0.12 \\
0.89 \pm 0.07\end{array}$ & $51(2.93 \%)$ \\
\hline
\end{tabular}

The positions of the MLH1 foci along chromosome arms were evaluated as their relative distance from the centromere (measured as \% of the SC arm length) and are given as means \pm SD. The total number of evaluated SC arms was 1,740 in both species. In cattle and sheep, 8 and 3 SCs, respectively, lacked MLH1 foci.

distances between recombination events. If a single $\mathrm{CO}$ event was present on an SC arm, it was usually located in the center of the SC arm (cattle median 55.2\%, sheep median 52.5\%). When 2 MLH1 foci were present on an SC arm, they were usually localized at the opposite ends of the SC arm. In the case of 3 or 4 CO events, they were equally distributed along the axis of the SC (table 4). Despite different total MLH1 foci counts and overall SC length in cattle and sheep, significant differences $(\mathrm{p}<$ 0.05 ) in the relative distribution of $\mathrm{CO}$ foci along all SCs were observed only in the case of $2 \mathrm{MLH} 1$ foci per SC arm.

Regarding bovine chromosomes BTA1, 2, 3, 5, 8, and 11 and their orthologs in sheep and goats, significant dif- ferences were found in the distribution of recombination sites along these SCs (table 5), especially if 3 MLH1 foci were present on the SC ( $<<0.001)$ (fig. 3$)$. The greatest disparity was observed in the distribution of the first and second proximal MLH1 foci on these SCs ( $p<0.001$ and $\mathrm{p}=0.003$, respectively), but no difference was observed in the location of the third, most distal MLH1 event ( $p>$ $0.05)$. Similarly, in the case of 2 recombination events per $\mathrm{SC}$, a significant difference was manifested in the position of the proximal MLH1 focus ( $\mathrm{p}<0.001$ ), but not in the distal recombination event (table 5).

\section{Discussion}

Species from the family Bovidae differ from each other in their diploid chromosome number due to numerous Robertsonian fusions of the ancestral acrocentric chromosomes (still present in cattle and goats, $2 n=60$ ), but are very similar in the fundamental number of autosomal arms ( $\mathrm{FNa}=58$ in most bovid species) [Gallagher et al., 1994]. Due to the same FNa, and assuming that there is a strong correlation in mammals between the number of chromosomal arms ( $\mathrm{FNa}$ ) and the number of mandatory COs, which are required for correct chromosome segregation [Pardo-Manuel de Villena and Sapienza, 2001; Lynn et al., 2002; Kauppi et al., 2004], similar recombination rates would be expected among the members of the family Bovidae. With the use of immunofluorescent labeling of proteins involved in the meiotic recombination process, we were able to perform a comparative study of $\mathrm{CO}$ numbers, their distribution on chromosomes, as well as other characteristics of recombination in spermatocytes of 4 species from the family Bovidae. We mainly focused on the economically important domestic species from this group (B. taurus, O. aries, C. hircus). Ammotra- 
Table 5. Distribution of MLH1 foci along SC arms corresponding to bovine chromosomes BTA1, 2, 3, 5, 8, and 11 in cattle, sheep and goats

\begin{tabular}{|c|c|c|c|c|c|c|c|}
\hline \multirow{2}{*}{$\begin{array}{l}\text { MLH1 } \\
\text { foci, } n\end{array}$} & & \multicolumn{2}{|l|}{ Cattle } & \multicolumn{2}{|l|}{ Sheep } & \multicolumn{2}{|l|}{ Goats } \\
\hline & & $\begin{array}{l}\text { MLH1 } \\
\text { position }\end{array}$ & SCs/arms, n & $\begin{array}{l}\text { MLH1 } \\
\text { position }\end{array}$ & SCs/arms, n & $\begin{array}{l}\text { MLH1 } \\
\text { position }\end{array}$ & SCs/arms, n \\
\hline 1 & 1 st & $0.49 \pm 0.21$ & $69(5.67 \%)$ & $0.58 \pm 0.27$ & $10(1.92 \%)$ & $0.52 \pm 0.26$ & $1(0.27 \%)$ \\
\hline 2 & $\begin{array}{l}1 \mathrm{st} \\
2 \mathrm{nd}\end{array}$ & $\begin{array}{l}0.24 \pm 0.13 \\
0.79 \pm 0.14\end{array}$ & $859(70.64 \%)$ & $\begin{array}{l}0.28 \pm 0.13 \\
0.82 \pm 0.13\end{array}$ & $170(32.63 \%)$ & $\begin{array}{l}0.19 \pm 0.14 \\
0.79 \pm 0.16\end{array}$ & $107(29.23 \%)$ \\
\hline 3 & $\begin{array}{l}1 \mathrm{st} \\
2 \mathrm{nd} \\
3 \mathrm{rd}\end{array}$ & $\begin{array}{l}0.14 \pm 0.08 \\
0.52 \pm 0.12 \\
0.91 \pm 0.11\end{array}$ & $284(23.36 \%)$ & $\begin{array}{l}0.18 \pm 0.10 \\
0.54 \pm 0.12 \\
0.89 \pm 0.09\end{array}$ & $279(53.55 \%)$ & $\begin{array}{l}0.11 \pm 0.08 \\
0.52 \pm 0.13 \\
0.89 \pm 0.10\end{array}$ & $214(58.47 \%)$ \\
\hline 4 & $\begin{array}{l}1 \text { st } \\
2 \text { nd } \\
3 \text { rd } \\
4 \text { th }\end{array}$ & $\begin{array}{l}0.09 \pm 0.02 \\
0.36 \pm 0.09 \\
0.54 \pm 0.16 \\
0.88 \pm 0.07\end{array}$ & $4(0.33 \%)$ & $\begin{array}{l}0.11 \pm 0.07 \\
0.38 \pm 0.10 \\
0.67 \pm 0.10 \\
0.93 \pm 0.07\end{array}$ & $62(11.91 \%)$ & $\begin{array}{l}0.08 \pm 0.06 \\
0.36 \pm 0.11 \\
0.66 \pm 0.11 \\
0.93 \pm 0.09\end{array}$ & $44(12.02 \%)$ \\
\hline
\end{tabular}

The positions of the MLH1 foci along chromosome arms were evaluated as their relative distance from the centromere (measured as \% of the SC arm length) and are given as means \pm SD. The total number of SCs was 1,216 in cattle, 521 in sheep and 366 in goats.

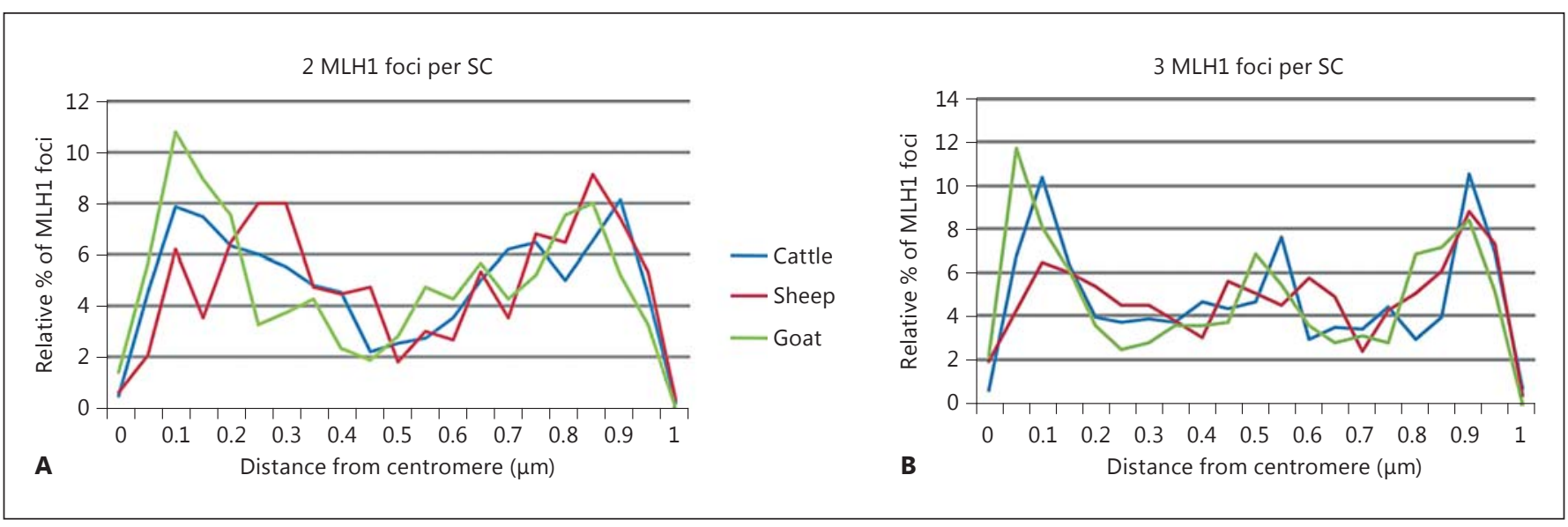

Fig. 3. Distribution of MLH1 foci on the SCs corresponding to chromosomes BTA1, 2, 3, 5, 8, and 11 in cattle, sheep and goats in the case of 2 (A) and 3 (B) MLH1 foci per SC arm.

gus lervia, a wildlife species from the tribe Caprini, was included in this study for the purpose of ascertaining whether or not the high meiotic recombination rates observed among Caprini are characteristic of the whole taxon or if they are caused by specific conditions during domestication (selection process) of sheep and goats [RossIbarra, 2004].

The mean numbers of COs per cell differed significantly among the studied species ( $47.5 \pm 4.3$ in cattle, 62.9 \pm 6.04 in sheep, $60.6 \pm 5.21$ in goats, and $57.95 \pm 5.03$ in Barbary sheep), and significant differences were found even amongst individual animals of the same species (online suppl. table 1), as was described elsewhere [Lynn et al., 2002; Sun et al., 2004]. Generally, significantly higher recombination rates were observed in sheep, goats and Barbary sheep (tribe Caprini) in comparison with cattle. This suggests that the high $\mathrm{CO}$ number is common for the species from the tribe Caprini and appears to be 
in compliance with the statement that closely related species tend to have similar recombination rates [Dumont and Payseur, 2008, 2011; Garcia-Cruz et al., 2011]. Considering the evolutionary context, species that diverged earlier in the evolutionary tree seem to have lower recombination rates than those from more derived phylogenetic branches [Segura et al., 2013]. It has been estimated that the divergence between Bovinae and Caprinae may date back more than 20 million years [Robinson and Ropiquet, 2011], whereas the divergence between goats and sheep may have occurred 5 million years ago [Ropiquet and Hassanin, 2005]. This can explain the elevated CO rates in Caprinae, as an evolutionary younger taxon. Regarding Caprinae, more $\mathrm{CO}$ events were present in goats and sheep than in Barbary sheep, which could be explained by the process of domestication that favors higher recombination rates in these 2 species [Ross-Ibarra, 2004]. However, only 1 specimen of Barbary sheep was available for this study and, considering the individual variability within species, the evidence for the effect of domestication is weak and demands further research.

There are many other factors which influence both species-specific and individual recombination rates. For example, Korol and Preygel [1994] and Butlin [2005] propose that species-specific recombination rates are influenced by the environment and environmental stress. When a species is located in a stressful environment, changes towards more $\mathrm{CO}$ events enable adaptation by disrupting current gene associations and create new combinations that can be advantageous in the new environment and conditions. Among species characteristics, age at maturity and lifespan values are also positively correlated with an increase in recombination rates, where recombination is favored in species with long generation times because these species experience more environmental changes during their longer lifespans [Korol and Preygel, 1994; Butlin, 2005]. However, this statement seems to contradict our data because recombination rates in cattle are significantly lower than in the species from the tribe Caprini, despite a longer lifespan (22 years in cattle vs. 15 years in sheep and goats) and generation time.

Our data, showing higher recombination rates in Caprini, are in accordance with the lengths of the published linkage maps. In this study, assuming that $1 \mathrm{MLH} 1$ focus $=1 \mathrm{CO}=50 \mathrm{cM}$, the male autosomal genetic map lengths were 2,393 cM, 3,187 cM and 3,026 cM in cattle, sheep and goats, respectively. This is less than the published autosomal linkage map lengths in cattle $(3,097$
cM) [Arias et al., 2009] and sheep (3,500 cM) [Maddox et al., 2001]. This could be caused by asynchronous MLH1 foci formation or by an MLH1-independent recombination which will make some COs undetectable by immunofluorescence analysis of the MLH1 protein. Discrepancies may also be caused by the fact that the linkage maps are gender-averaged because a higher $\mathrm{CO}$ rate was reported in females than in males, both in humans and mice [Froenicke et al., 2002; Sun et al., 2004]. The length of the autosomal genetic map of Barbary sheep $(2,897 \mathrm{cM})$ is similar to the length of the male autosomal genetic map of another wild Caprini species, Bighorn sheep (Ovis canadensis, 2,831 cM) [Poissant et al., 2010], despite the fact that Bighorn sheep have the same 3 Robertsonian fusions in the genome as the domestic sheep. This can be another proof for the domestication hypothesis.

SCs lacking MLH1 foci were scarce in all studied species. Thus, the statement about 1 obligatory recombination event per chromosome or chromosomal arm [Pardo-Manuel de Villena and Sapienza, 2001; Segura et al., 2013] was generally maintained. Despite the same number of autosomal arms in all studied species $(\mathrm{FNa}=58)$, the observed recombination rate in sheep was higher than in the other 3 related species. This is even more surprising when we realize that the sheep genome contains 3 Robertsonian fusions $(2 n=54)$ which are supposed to be responsible for a reduction of recombination on fused chromosomes [Dumas and Britton-Davidian, 2002; Merico et al., 2013; Vozdova et al., 2013; Capilla et al., $2014]$. The increased recombination rates in sheep $(33.1 \%$ above the mean in cattle) were associated with only a minor elevation of the total autosomal SC length (7.5\%) which resulted in higher recombination density in sheep $(0.244 \pm 0.021)$ being one of the highest reported so far [Borodin et al., 2007; Segura et al., 2013]. In this study, the lowest recombination density was observed in goats, which is caused by a highly elevated total SC length $(34.4 \%$ above the total SC length in cattle) without a concordant increase in recombination rates (only 25.3\% increase of recombination compared to cattle). Interestingly, recombination densities in cattle and Barbary sheep were similar despite their different total SC lengths and MLH1 foci counts (table 1).

With no significant difference in the length of whole genomes of the studied species, the significant increase in the total length of SCs associated with increased recombination rates in Caprinae compared with cattle can be explained by a different degree of DNA condensation into the chromatin loops when SCs are formed in meiosis. 
Chromatin packaged into more loops is supposed to undergo more double-strand breaks (DSBs), which can be resolved as CO events [Kleckner et al., 2003; Kauppi et al., 2012]. However, it was shown that the variation in the number of recombination events more likely reflects differences in chromatin morphology than the number of DSBs identified as RAD51 foci [Baier et al., 2014].

The effect of Robertsonian fusions on recombination rates and distribution was studied in detail in ovine metacentric chromosomes. The relative proportion of MLH1 foci that were present on the acrocentric chromosomes BTA 1, 2, 3, 5, 8, and 11 and their acrocentric orthologs in goats (calculated as a percentage of MLH1 foci located on the referred chromosomes, divided by the total number of all autosomal MLH1 foci in the cell) was significantly higher than on the orthologous metacentrics in sheep (27.6 and $28.2 \%$ in cattle and goats vs. $26.1 \%$ in sheep). The minor increase in recombination rates on BTA1, 2, $3,5,8$, and 11 orthologs in goats compared with cattle is probably associated with the greater physical length of the caprine SCs, which can provide more space for the assembly of additional recombination nodules. Interestingly, the recombination rates on the SCs of ovine metacentric chromosomes were reduced despite their higher relative length $(30.27 \%$ of the total length of all SCs in the cell) compared to the orthologous acrocentrics in cattle and goats (28.94 and $27.88 \%$ of the total SC length, respectively). The observed reduction of the recombination in the metacentric chromosomes in sheep was not caused by a loss of genetic material in fused chromosomes as previously proposed in other bovids [Vozdova et al., 2013], because no significant differences were found in the relative mitotic lengths of sheep metacentric chromosomes compared with their acrocentric orthologs in cattle. Also, the bovine, ovine and goat genomic libraries available at the NCBI database show similar whole genome sizes, as well as the sizes of the individual chromosomes focused upon in this study (table 3).

Taking zero genome shortening and a higher relative SC length of metacentric chromosomes in sheep into account, the relative reduction of recombination in the fused chromosomes is probably associated with their metacentric morphology, as it was observed in human and pig bi-armed chromosomes [Lian et al., 2008; Merico et al., 2013; Mary et al., 2014]. It is well known that meiotic recombination is repressed close to the centromeres, although the molecular mechanism underlying centromere interference is still largely unknown [Hassold et al., 2000; Youds and Boulton, 2011]. One of the possible explanations of the recombination suppression is thought

Meiotic Recombination in Cattle, Sheep and Goats to be the more condensed and methylated state of pericentromeric heterochromatin [Lynn et al., 2004; Capilla et al., 2014]. In fact, the epigenetic status of the chromatin is, in general, important for recombination. Meiotic DSBs have the tendency to occur in open and highly transcribed regions with euchromatin [Smagulova et al., 2011], whereas DNA methylation suppresses CO formation. Recent studies have demonstrated that centromere activity itself exerts the recombination suppression effect, which can be distinguished from the heterochromatin effect.

Another explanation is associated with the phenomenon of $\mathrm{CO}$ interference. Generally, the distribution of MLH1 foci along all SCs in sheep and cattle was non-random, which suggests the involvement of interference or some other directing mechanism. If a single MLH1 focus was present on an SC arm, it was usually located in the center. This differs from the data published for humans, mice and pigs, showing the concentration of recombination events in the distal chromosome regions in males [Anderson et al., 1999; Froenicke et al., 2002; Sun et al., 2004; Mary et al., 2014].

Inhibition of the $\mathrm{CO}$ by the centromere was experimentally proven in yeast [Lambie and Roeder, 1986]. Preferential formation of DSBs on axial elements away from the centromeres was observed in mice [Mahadevaiah et al., 2001]. The proximal CO suppression in metacentrics can be associated with the spatial organization of chromosomes in the meiotic cell nucleus. During formation of the axial element and initiation of chromatid pairing, telomeres are connected with the nuclear envelope [Scherthan et al., 1996]. This brings the distal regions of chromosomes to a spatial proximity which can lead to $\mathrm{CO}$ formation. According to the mechanical model for $\mathrm{CO}$ interference, the distal recombination events which are formed earlier during meiosis, limit formation of proximal COs [Kleckner et al., 2004]. Thus, synapsis and CO formation on the bi-armed chromosomes proceeds from both distal ends towards the centromeric regions, which are located in the nuclear interior, and their recombination is therefore delayed and possibly suppressed.

Other significant differences, which support the centromeric interference hypothesis, were found in the distribution of MLH1 foci along the SCs of metacentric chromosomes in sheep and their acrocentric orthologs in cattle and goats (BTA1, 2, 3, 5, 8, and 11), especially in the presence of $3 \mathrm{MLH} 1$ foci on these SCs with the biggest disparity observed in the distribution of the first and second proximal MLH1 foci (fig. 3; table 5). Differences in the distribution of MLH1 foci on the individual chromo- 
somes BTA1, 2, 3, 5, 8, and 11 and their sheep orthologs are displayed in online supplementary table 2 . This could be caused by the mechanism of the assembly of the SC axes, which begins from telomeric regions and progresses towards the centromere [Barlow and Hultén, 1996; Scherthan et al., 1996; Brown et al., 2005], so the first recombination is established near the end of the SC without any interference. Simultaneously, the proximal MLH1 focus is influenced by a centromeric interference (especially in metacentric chromosomes) with a shift of its position to the distal part of the SC. Such a distal shift was observed previously in mice with Robertsonian fusions [Bidau et al., 2001; Dumas and Britton-Davidian, 2002; Capilla et al., 2014]. The position of the second recombination event, in the case of 3 MLH1 foci per SC, is less variable than the proximal MLH1 focus position because it is adjusted from both sides by adjacent MLH1 foci. This could cause the double peak in its distribution (fig. 3B) along the physically longer SCs of the $3 \mathrm{bi}$-armed sheep chromosomes, thus providing an additional space for variable and more distal positioning of the second MLH1 focus under the pressure of interference.

\section{Conclusion}

Regardless of the evolutionary relationships among the studied species from the family Bovidae, significant differences in recombination rates were observed between the Bovini and Caprini tribes, which can be explained by the length of time that has passed since their evolutionary divergence. However, significant differences were also found even amongst individuals of the same species. Despite the significantly higher frequency of recombination in Caprini, the recombination rate in metacentric chromosomes of evolutionary origin in sheep seems to be affected by the presence of the Robertsonian fusions.

\section{Acknowledgements}

The authors wish to thank Mr. Paul Veater (Bristol, UK) for proofreading the translated manuscript. This work was supported by grant P502/11/0719 from the Grant Agency of the Czech Republic and CEITEC - Central European Institute of Technology (ED1.1.00/02.0068) from the European Regional Development Fund.

\section{References}

Al-Jaru A, Goodwin W, Skidmore J, Khazanehdari K: Distribution of MLH1 foci in horse male synaptonemal complex. Cytogenet $\mathrm{Ge}-$ nome Res 142:87-94 (2014).

-Anderson LK, Reeves A, Webb LM, Ashley T: Distribution of crossing over on mouse synaptonemal complexes using immunofluorescent localization of MLH1 protein. Genetics 151:1569-1579 (1999).

-Arias JA, Keehan M, Fisher P, Coppieters W, Spelman R: A high density linkage map of the bovine genome. BMC Genet 10:18 (2009).

Baier B, Hunt P, Broman KW, Hassold T: Variation in genome-wide levels of meiotic recombination is established at the onset of prophase in mammalian males. PLoS Genet 10: e1004125 (2014).

- Baker SM, Plug AW, Prolla TA, Bronner CE, Harris $\mathrm{AC}$, et al: Involvement of mouse Mlh1 in DNA mismatch repair and meiotic crossing over. Nat Genet 13:336-342 (1996).

- Barlow AL, Hultén MA: Combined immunocytogenetic and molecular cytogenetic analysis of meiosis I human spermatocytes. Chromosome Res 4:562-573 (1996).

- Barlow AL, Hultén MA: Crossing over analysis at pachytene in man. Eur J Hum Genet 6:350358 (1998).
Basheva EA, Bidau CJ, Borodin PM: General pattern of meiotic recombination in male dogs estimated by MLH1 and RAD51 immunolocalization. Chromosome Res 16:709-719 (2008).

Bidau CJ, Giménez MD, Palmer CL, Searle JB: The effects of Robertsonian fusions on chiasma frequency and distribution in the house mouse (Mus musculus domesticus) from a hybrid zone in northern Scotland. Heredity 87: 305-313 (2001).

Borodin PM, Karamysheva TV, Rubtsov NB: Immunofluorescent analysis of meiotic recombination in the domestic cat. Cell Tissue Biol 1:503-507 (2007).

- Borodin PM, Karamysheva TV, Belonogova NM, Torgasheva AA, Rubtsov NB, et al: Recombination map of the common shrew, Sorex araneus (Eulipotyphla, Mammalia). Genetics 178:621-632 (2008).

-Bovine Genome Sequencing and Analysis Consortium, Elsik CG, Tellam RL, Worley KC, Gibbs RA, Muzny DM, et al: The genome sequence of taurine cattle: a window to ruminant biology and evolution. Science 324:522528 (2009).

Brown PW, Judis L, Chan ER, Schwartz S, Seftel A, et al: Meiotic synapsis proceeds from a limited number of subtelomeric sites in the human male. Am J Hum Genet 77:556-566 (2005).
Butlin RK: Recombination and speciation. Mol Ecol 14:2621-2635 (2005).

Capilla L, Medarde N, Alemany-Schmidt A, Oliver-Bonet $\mathrm{M}$, Ventura J, Ruiz-Herrera A: Genetic recombination variation in wild Robertsonian mice: on the role of chromosomal fusions and $\operatorname{Prdm} 9$ allelic background. Proc Biol Sci 281:20140297 (2014).

Cohen PE, Pollack SE, Pollard JW: Genetic analysis of chromosome pairing, recombination, and cell cycle control during first meiotic prophase in mammals. Endocr Rev 27:398-426 (2006).

Coop G, Przeworski M: An evolutionary view of human recombination. Nat Rev Genet 8:2334 (2007).

Dong Y, Xie M, Jiang Y, Xiao N, Du X, et al: Sequencing and automated whole-genome optical mapping of the genome of a domestic goat (Capra hircus). Nat Biotechnol 31:135141 (2013).

Dumas D, Britton-Davidian J: Chromosomal rearrangements and evolution of recombination: comparison of chiasma distribution patterns in standard and Robertsonian populations of the house mouse. Genetics 162: 1355-1366 (2002).

Dumont BL, Payseur BA: Evolution of the genomic rate of recombination in mammals. Evolution 62:276-294 (2008). 
Dumont BL, Payseur BA: Evolution of the genomic recombination rate in murid rodents. Genetics 187:643-657 (2011).

-Fledel-Alon A, Wilson DJ, Broman K, Wen X, Ober $\mathrm{C}$, et al: Broad-scale recombination patterns underlying proper disjunction in humans. PLoS Genet 5:e1000658 (2009).

-Froenicke L, Anderson LK, Wienberg J, Ashley T: Male mouse recombination maps for each autosome identified by chromosome painting. Am J Hum Genet 71:1353-1368 (2002).

-Gallagher DS, Derr JN, Womack JE: Chromosome conservation among the advanced pecorans and determination of the primitive bovid karyotype. J Hered 85:204-210 (1994).

-Garcia-Cruz R, Pacheco S, Brieño MA, Steinberg ER, Mudry MD, et al: A comparative study of the recombination pattern in three species of Platyrrhini monkeys (primates). Chromosoma 120:521-530 (2011).

-Groenen MAM, Wahlberg P, Foglio M, Cheng $\mathrm{HH}$, Megens HJ, et al: A high-density SNPbased linkage map of the chicken genome reveals sequence features correlated with recombination rate. Genome Res 19:510-519 (2009).

-Hassanin A, Douzery EJP: The tribal radiation of the family Bovidae (Artiodactyla) and the evolution of the mitochondrial cytochrome $b$ gene. Mol Phylogenet Evol 13:227-243 (1999).

Hassold T, Sherman S, Hunt P: Counting crossovers: characterizing meiotic recombination in mammals. Hum Mol Genet 9:2409-2419 (2000).

Hultén M: Chiasma distribution at diakinesis in the normal human male. Hereditas 76:55-78 (1974).

International Sheep Genomics Consortium, Archibald AL, Cockett NE, Dalrymple BP, Faraut $\mathrm{T}$, et al: The sheep genome reference sequence: a work in progress. Anim Genet 41: 449-453 (2010).

-Jensen-Seaman MI, Furey TS, Payseur BA, Lu Y, Roskin KM, et al: Comparative recombination rates in the rat, mouse, and human genomes. Genome Res 14:528-538 (2004).

-Kauppi L, Jeffreys AJ, Keeney S: Where the crossovers are: recombination distributions in mammals. Nat Rev Genet 5:413-424 (2004).

Kauppi L, Jasin M, Keeney S: The tricky path to recombining $\mathrm{X}$ and $\mathrm{Y}$ chromosomes in meiosis. Ann NY Acad Sci 1267:18-23 (2012).

-Kleckner N, Storlazzi A, Zickler D: Coordinate variation in meiotic pachytene SC length and total crossover/chiasma frequency under conditions of constant DNA length. Trends Genet 19:623-628 (2003).
Kleckner N, Zickler D, Jones GH, Dekker J, Padmore R, et al: A mechanical basis for chromosome function. Proc Natl Acad Sci USA 101: 12592-12597 (2004).

Kong A, Gudbjartsson DF, Sainz J, Jonsdottir GM, Gudjonsson SA, et al: A high-resolution recombination map of the human genome. Nat Genet 31:241-247 (2002).

Korol AB, Preygel SI: Recombination Variability and Evolution. Algorithms of Estimation and Population-Genetic Models (Chapman \& Hall, London 1994).

Kubickova S, Cernohorska H, Musilova P, Rubes $\mathrm{J}$ : The use of laser microdissection for the preparation of chromosome-specific painting probes in farm animals. Chromosome Res 10: 571-577 (2002).

Lambie EJ, Roeder GS: Repression of meiotic crossing over by a centromere (CEN3) in Saccharomyces cerevisiae. Genetics 114:769-789 (1986).

Lian J, Yin Y, Oliver-Bonet M, Liehr T, Ko E, et al: Variation in crossover interference levels on individual chromosomes from human males. Hum Mol Genet 17:2583-2594 (2008).

Lynn A, Koehler KE, Judis L, Chan ER, Cherry JP, et al: Covariation of synaptonemal complex length and mammalian meiotic exchange rates. Science 296:2222-2225 (2002).

Lynn A, Ashley T, Hassold T: Variation in human meiotic recombination. Annu Rev Genomics Hum Genet 5:317-349 (2004).

Maddox JF, Davies KP, Crawford AM, Hulme DJ, Vaiman D, et al: An enhanced linkage map of the sheep genome comprising more than 1000 loci. Genome Res 11:1275-1289 (2001).

Mahadevaiah SK, Turner JM, Baudat F, Rogakou EP, de Boer P, et al: Recombinational DNA double-strand breaks in mice precede synapsis. Nat Genet 27:271-276 (2001).

- Mary N, Barasc H, Ferchaud S, Billon Y, Meslier $\mathrm{F}$, et al: Meiotic recombination analyses of individual chromosomes in male domestic pigs (Sus scrofa domestica). PLoS One 9:e99123 (2014).

- Merico V, Giménez MD, Vasco C, Zuccotti M, Searle JB, et al: Chromosomal speciation in mice: a cytogenetic analysis of recombination. Chromosome Res 21:523-533 (2013).

Pardo-Manuel de Villena F, Sapienza C: Recombination is proportional to the number of chromosome arms in mammals. Mamm Genome 12:318-322 (2001).

Poissant J, Hogg JT, Davis CS, Miller JM, Maddox JF, et al: Genetic linkage map of a wild genome: genomic structure, recombination and sexual dimorphism in bighorn sheep. BMC Genomics 11:524 (2010).
Robinson TJ, Ropiquet A: Examination of hemiplasy, homoplasy and phylogenetic discordance in chromosomal evolution of the Bovidae. Syst Biol 60:439-450 (2011).

Robinson WP: The extent, mechanism, and consequences of genetic variation, for recombination rate. Am J Hum Genet 59:1175-1183 (1996).

Ropiquet A, Hassanin A: Molecular evidence for the polyphyly of the genus Hemitragus (Mammalia, Bovidae). Mol Phylogenet Evol 36: 154-168 (2005).

Ross-Ibarra J: The evolution of recombination under domestication: a test of two hypotheses. Am Nat 163:105-112 (2004).

- Scherthan H, Weich S, Schwegler H, Heyting C, Härle $\mathrm{M}$, Cremer T: Centromere and telomere movements during early meiotic prophase of mouse and man are associated with the onset of chromosome pairing. J Cell Biol 134:1109-1125 (1996).

-Sciurano RB, Rahn MI, Rey-Valzacchi G, Coco R, Solari AJ: The role of asynapsis in human spermatocyte failure. Int J Androl 35:541-549 (2012).

-Segura J, Ferretti L, Ramos-Onsins S, Capilla L, Farré M, et al: Evolution of recombination in eutherian mammals: insights into mechanisms that affect recombination rates and crossover interference. Proc Biol Sci 280: 20131945 (2013).

-Smagulova F, Gregoretti IV, Brick K, Khil P, Camerini-Otero RD, Petukhova GV: Genome-wide analysis reveals novel molecular features of mouse recombination hotspots. Nature 472:375-378 (2011).

Sun F, Oliver-Bonet M, Liehr T, Starke H, Ko E, et al: Human male recombination maps for individual chromosomes. Am J Hum Genet 74:521-531 (2004).

-Vozdova M, Sebestova H, Kubickova S, Cernohorska H, Vahala J, Rubes J: A comparative study of meiotic recombination in cattle (Bos taurus) and three wildebeest species (Connochaetes gnou, C. taurinus taurinus and C. $t$. albojubatus). Cytogenet Genome Res 140:3645 (2013).

Yang Q, Zhang D, Leng M, Yang L, Zhong L, et al: Synapsis and meiotic recombination in male Chinese muntjac (Muntiacus reevesi). PLoS One 6:e19255 (2011).

Youds JL, Boulton SJ: The choice in meiosis - defining the factors that influence crossover or non-crossover formation. J Cell Sci 124:501513 (2011). 